Case Report

\title{
Hemiatrophy of the brain: a report of two cases
}

\author{
Shrestha RK, Sedain G, Shilpakar SK \\ Neurosurgical unit, Department of surgery, Tribhuvan University Teaching Hospital \\ Correspondence: Ram Kumar Shrestha, Neurosurgical Unit, Department of Surgery, Tribhuvan University Teaching \\ Hospital, PO Box 3578, Maharajgunj, Kathmandu, Nepal,
}

Email: recti90@gmail.com

\begin{tabular}{l} 
Abstract \\
\hline \hline Introduction: Hemiatrophy of the brain is the radiological finding, in the patients with seizure and/ \\
or mental retardation and hemiparesis, usually due to insult to developing brain in fetal and early \\
childhood. Other imaging feature is the compensatory osseous hyperplasia. This condition, also \\
known as Dyke-Davidoff-Masson Syndrome is a rare entity and we report two such cases. \\
Key Words: Hemiatrophy; Dyke-Davidoff-Masson Syndrome; Seizure
\end{tabular}

\section{Introduction}

Hemiatrophy of the brain is defined as atrophy or hypoplasia of one side of cerebral hemisphere and is occasionally seen on screening radiologic images performed for the evaluation of patients presenting with seizure and/or developmental delay. ${ }^{1}$ This is usually the end result of an insult to the developing brain in fetal or early childhood period. ${ }^{1}$ The resultant cerebral volume reduction renders several morphologic changes in the brain and skull. The radiological description of cerebral hemiatrpohy was first reported in 1933 by Dyke and colleagues and thus, this is also termed Dyke-DavidoffMasson Syndrome (DDMS). ${ }^{2}$ The typical clinical presentation include generalized seizure, hemiparesis or hemiplegia, mental retardation and facial asymmetry. ${ }^{3}$

Here, we are reporting two such cases with typical clinical and radiographic presentation of Dyke-DavidoffMasson Syndrome.

\section{Case 1:}

A 7-year-old girl child presented with recurrent generalized seizure for one year. There was no significant complication during the antenatal and perinatal period. The developmental and growth milestones were normal. On clinical history, she walked with a limp and had mild weakness of her left extremities; but her facial symmetry was maintained. Carotid pulsation was comparable on both sides; and there was no audible bruit on auscultation of the neck. The vision and hearing were normal. On neurological examination, there was no cranial nerve deficit. However, she had decreased power of $4 / 5$ on Medical Research Council (MRC) scale in the left upper and lower extremities. The bulk and the tone of the all muscle groups were normal and equal on both sides. The superficial and deep reflexes were found to be normal.

Magnetic Resonance Imaging (MRI) of brain revealed cerebral volume reduction in right cerebral hemisphere with opened sulci, atrophied gyri and prominent adjacent convexity cisterns. The white matter of right cerebral hemisphere was reduced in size. The right lateral ventricle was dilated as compared to the left side. (Figure 1) Additional CT scan findings on the bone window were ipsilateral displacement of falx cerebri, elevated right petrous bone and thickened ipsilateral calvarium. (Figure 2) She was kept on Sodium Valproate orally $200 \mathrm{mg}$ twice a day and was started on physiotherapy with gait training and left limb strengthening exercise. Currently, she has been seizure free for 5 months; and she is on regular follow up in the Neurosurgical out Patient Clinic. 


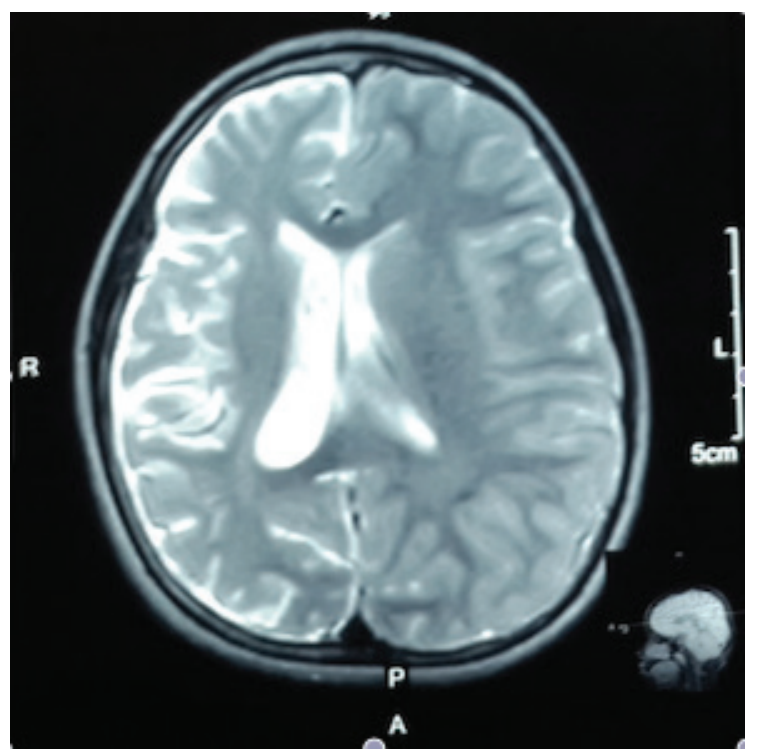

Figure 1: MRI brain showing dilated lateral ventricles

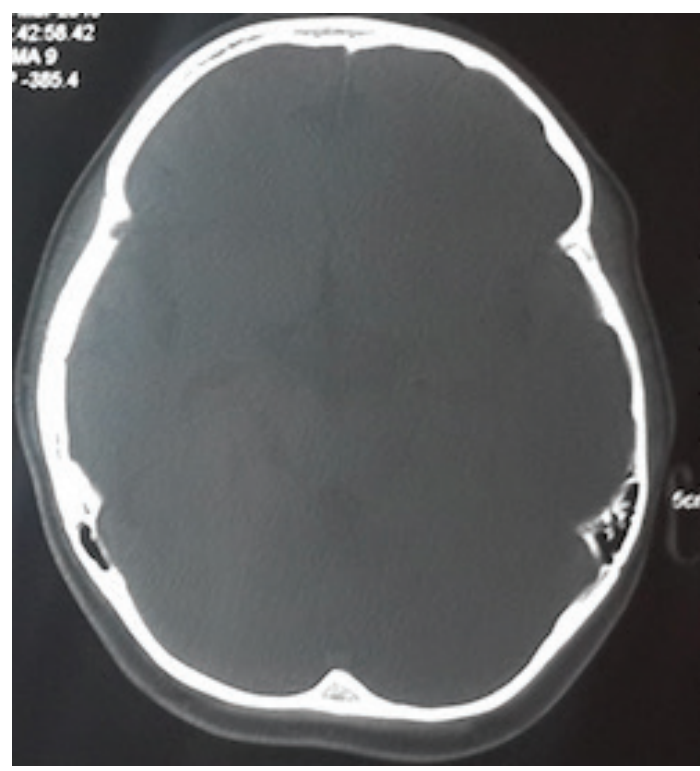

Figure 2: CT-scan head, bone window showing ipsilateral displacement of falxcerebri, elevated right petrous bone and thickened ipsilateral calvarium.

\section{Case 2:}

A 17-year-old adolescent presented to Emergency Department with status epilepticus who was urgently managed with intravenous Phenytoin, loading dose of $900 \mathrm{mg}(15 \mathrm{mg} / \mathrm{Kg})$. Clinical history revealed significant delayed developmental and growth milestones; and the patient required special care at home. He had history of recurrent generalized seizure, starting from the childhood age of five; however, he was never on antiepileptic drug (AED). Neurological examination revealed right-sided facial deviation, together with spastic hemiparesis of right upper and lower extremities.

CT-scan revealed prominent sulci, atrophied gyri and relatively enlarged ventricle on the left cerebral hemisphere. (Figure 3) Additionally, the skull was found to be more thickened on the left side. (Figure 4) Subsequently, he was kept on maintenance dose 300 $\mathrm{mg}$ of oral Phenytoin ( $5 \mathrm{mg} / \mathrm{Kg} /$ day) and discharged from emergency and advised for regular follow up and continue physiotherapy.

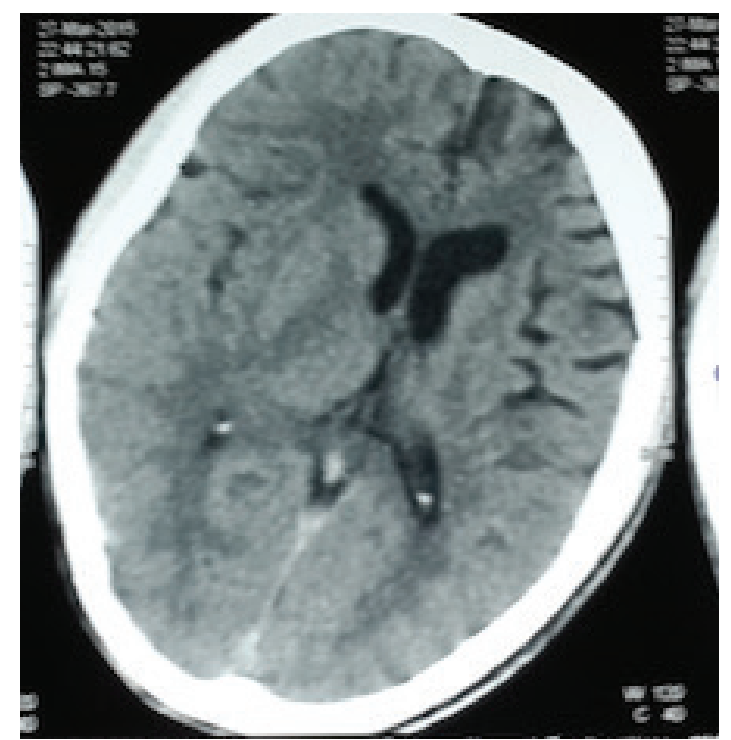

Figure 3: CT scan head showing prominent sulci

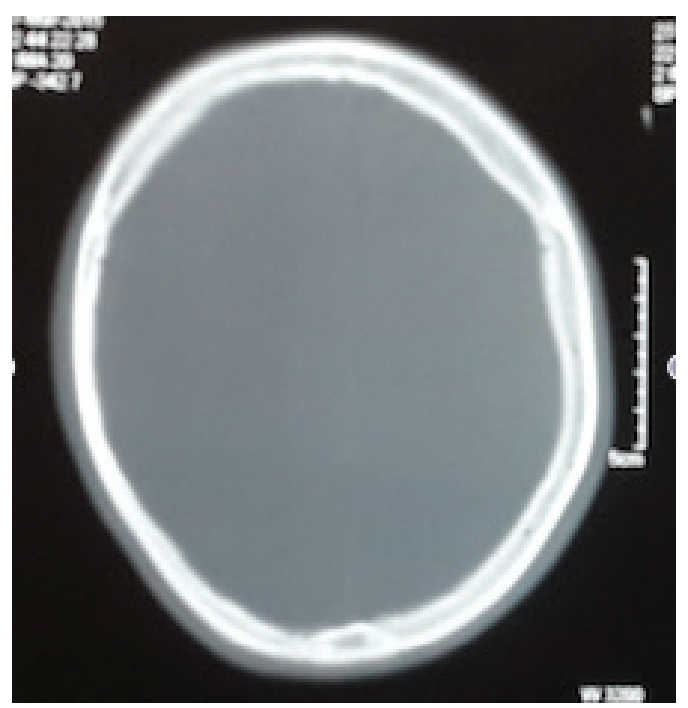

Figure 4: CT scan head showing thickening of skull on left side 


\section{Discussion}

First described by Dyke, Davidoff and Masson in 1933, the syndrome is characterized by asymmetrical cerebral hemispheric growth with atrophy or hypoplasia of one side and ipsilateral osseous hypertrophy. Ipsilateral sulci enlargement, ipsilateral cisternal space and ventricle dilatation and midline shift are also found. ${ }^{2,6}$ Both of our patients' imaging characteristics are in sync with that of typical DDMS with atrophy of parenchyma and compensatory bone hypertrophy.

The usual presentations include recurrent seizure- focal or generalized, contralateral hemiparesis, delayed developmental milestone/mental retardation, facial asymmetry, etc. ${ }^{3}$ Our patients had all the features except for the facial skeletal hypertrophy. Facial asymmetry in the second case is due to facial nerve palsy rather than asymmetrical osseous hypertrophy.

The etiology of this condition can be either congenital or acquired. Congenital causes can be related to idiopathic or intrauterine cerebral vascular insult. Acquired etiology may include any trauma, infection, infarction or hemorrhage during developmental stage of brain. Hereby, any vascular insult, whether congenital or acquired, commonly involving the middle cerebral artery (MCA) during brain development and growth can lead to Dyke-DavidoffMasson syndrome. ${ }^{1,4}$ As brain reaches three-fourths of the adult size by third year of birth, any insult before age 3 most likely lead to hemiatrophy on the ipsilateral side and compensatory hypertrophy of brain on the contralateral side. The diploic spaces widened and sinuses enlarged for inward growth of calvarial structure to compensate for poor growth on the affected side. ${ }^{3,5}$ Due to poor prenatal and antenatal visit and unavailability of medial records, it is difficult to ascertain the etiology in our patients. Any of the above-mentioned cause could have incite the vicious cycle of vascular insufficiency to developing brain leading to the present condition.

As DDMS usually present with recurrent seizure and hemiparesis, the management is mainly directedtowards seizure control and physiotherapy. Special care may be required for the patient with mental retardation. Hemispherectomy may be required for failure to control refractory seizures in some patients. ${ }^{3}$

\section{References}

1. Uduma FU, Emejulu JC, Motah M, Okere PN, Ongolo PC, Muna W. Differential diagnoses of cerebral hemiatrophy in childhood: a review of literature with illustrated report of two cases. Global J Health Sci2013; 3: 195-207

2. Dyke CG, Davidoff LM, Masson LB. Cerebral hemiatrophy with homolateral hypertrophy of the skull and sinus. SurgGynecolObstet 1933; 57: 588-600.

3. Kumar S, Lakshmaiah V, Naidu K KC. A rare cause for seizures and mental retardation- Dyke Davidoff Masson Syndrome.Int J Biol Med Res 2011; 2: 1186-8

4. Aguiar PH, Liu CW, Leitao H, Issa F, Lepski G, Figueiredo EG et al. MR and CT imaging in the DykeDavidoff-Masson Syndrome. ArqNeuropsiquiatr1998; 56: 803-7.

5. Tasdemir HA, Incesu L, Yazicioglu AK, Belet U, Gungor L. Dyke Davidoff Masson syndrome. Clin Imaging 2002; 26: 13-17

6. Dix JE, Coil WS. Cerebral hemiatrophy: Classification on the basis of MR Imaging findings of mesial temporal sclerosis and childhood febrile seizures. Radiology 1997; 203: 269-274 